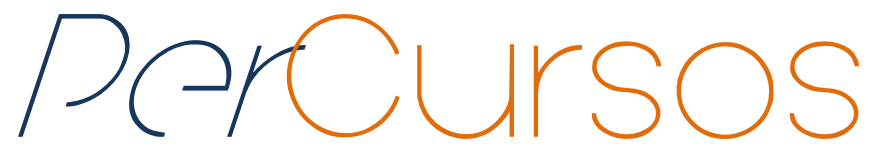

\title{
Cultura visual e paisagem: a topografia da Nova Holanda e a evocação da colônia açucareira no Brasil ${ }^{1}$
}

\section{Resumo}

O presente trabalho tem por objetivo a investigação de duas formas distintas de articular os motivos das figuras humanas e da faixa topográfica na estrutura das composições dos painéis Paisagem com rio e tatu e Paisagem com rio e tamanduá, de 1649, e no painel Paisagem com rio e índios, de 1650, todos executados por Frans Post (1612-1680), a fim de relacioná-las ao imaginário neerlandês sobre a terra do Brasil. Partindo de uma comparação iconográfica e considerando questões propostas pelos estudos de cultura visual, a hipótese aqui apresentada é a de que as composições nos quadros considerados constituíram a base para um repertório por meio do qual se tornou cada vez mais visível, no decorrer dos anos de 1650, dois imaginários sobre a colônia. Articuladas a projetos políticos diferentes, com implicações tanto para as definições de soberania quanto para a construção das identidades culturais, essas duas visões do Brasil foram se definindo em torno de estratégias visuais que urdiam a paisagem por meio da relação ora de representação topográfica de lugar ora de evocações indiscriminadas da terra, sem alusão a localidades específicas.

Palavras-chave: Cultura visual; Paisagem; História Moderna; Brasil holandês; Frans Post.

\author{
Daniel de Souza Leão Vieira \\ Doutor em Humanidades pela \\ Universiteit Leiden - Países \\ Baixos. Professor da \\ Universidade Federal de \\ Pernambuco - UFPE. \\ Brasil \\ dan.slvieira@gmail.com
}

Post.

\footnotetext{
${ }^{1}$ Projeto de pesquisa "Culturas do Passado Presente: um estudo sobre o discurso da novidade e as políticas patrimoniais em um Recife de três tempos", com apoio da Fundação de Amparo à Ciência e Tecnologia do Estado de Pernambuco - FACEPE.
} 


\title{
Visual culture and landscape: the topography of New Holland and the evocation of the Sugar Colony in Brazil
}

\begin{abstract}
This paper investigates two distinct forms of integrating the human figures and topographical band within composition structures on the panels Landscape with river and armadillo and Landscape with river and anteater, of 1649 , as well as on the panel Landscape with river and Indians, from 1650, all executed by Frans Post (1612-1680), in order to relate them to the Dutch imagination about Brazilian land. Based on iconographical comparison and considering questions raised by visual culture studies, the posed hypothesis here considers that those panels constituted the groundwork for a repertoire through which two visions of Brazil were made possible from 1650 s decade on. Articulated to different political projects, with implications both to sovereignty concepts and cultural identities, those two visions were embodied through visual strategies that constructed landscape sometimes by topographical representation and sometimes by indiscriminate evocation of land, without alluding to specific locations.
\end{abstract}

Keywords: Visual culture; Landscape; Early Modern History; Dutch Brazil; Frans Post.

\section{Para citar este artigo:}

VIEIRA, Daniel de Souza Leão Vieira. Cultura visual e paisagem: a topografia da Nova Holanda e a evocação da colônia açucareira no Brasil. Revista PerCursos, Florianópolis, v. 17, n.33, p. 08 - 31, jan./abr. 2016.

DOI: $\mathbf{1 0 . 5 9 6 5 / 1 9 8 4 7 2 4 6 1 7 3 3 2 0 1 6 0 0 8}$

http://dx.doi.org/10.5965/1984724617332016008 
A maior parte da bibliografia existente sobre Frans Post (1612-1680) é perpassada por um discurso que, relacionado à prática do connoisseurship, concebe a imagem como uma cópia do real. Ao reproduzir uma leitura mimética da paisagem, essa tradição terminou por restringir-se, na investigação da obra de Frans Post, a permanecer na superfície da evocação seiscentista de motivos edênicos e/ou arcádicos.

No entanto, encontramos brechas na historiografia da arte sobre Frans Post que apontavam para investigações que sugeriam que a imagem de arte fosse relacionada aos aspectos científicos e comerciais dos neerlandeses no Brasil do século XVII (FREEDBERG, 1999), bem como de uma descrição da vida social na colônia (BOOGAART, 2004). Portanto, das lacunas e aspectos negligenciados pelo discurso do realismo, e atravessando o escopo de investigações apenas sugeridas, pudemos então justificar um estudo da imagem em Frans Post enquanto documento iconográfico, ou fonte visual, para a investigação cultural da concepção de uma paisagem política e de como foi possível sua construção imaginária em relação à história do dito "Brasil holandês".

Como o debate sobre a relação entre paisagem e identidade pode seguir diversos caminhos, preferimos nos ater ao aspecto coletivo, procurando relacionar o imaginário de paisagem à construção cultural de uma identificação coletiva de pertença a um território comum. No entanto, porque essa construção cultural da paisagem está perpassada pelas relações de poder, a definimos então como uma paisagem política (OLWIG, 2002). Nesse sentido, foi importante rastrear os interesses dos grupos sociais neerlandeses sobre o Brasil a partir do estudo dos vestígios deixados por essa construção imagética e imaginária na produção artística de Frans Post, não sem antes problematizar a relação desse imaginário neerlandês sobre o Brasil com a questão da colonização em meio à expansão atlântica.

A hipótese que aqui apresentaremos, ainda que através de uma comparação iconográfica bastante específica, como se verá mais adiante, é a de que a imagem em Frans Post está relacionada à construção de visões neerlandesas sobre a Terra do Brasil, no século XVII, a partir do embate entre dois discursos. Esses, ao se associarem às estruturações das formas nas composições, deixaram um testemunho visual (BURKE, 2004) de forças que, polarizadas, nos permitem entrever as tensões sociais entre uma 
atitude política de colonização a partir da extensão da soberania ao território sob a posse da Geoctroyeerde West-Indische Compagnie - WIC - no Brasil; e uma outra atitude, não menos política, mas de ênfase econômica e que, interessada apenas na manutenção de uma mínima infra-estrutura de relevância geopolítica atlântica, a fim de permitir o acesso à produção de artigos tropicais que seriam comercializados nos mercados consumidores europeus, não implicava em incorporação da colônia na soberania.

A primeira dessas atitudes estava em consonância com o discurso orangistanassoviano, que, tendo como proponente o Stadhouder, Lugar-tenente, dos Estados da Holanda, da Zelândia e de Utrecht, Frederik Hendrik, Príncipe de Orange-Nassau, e o Governador-geral da Nova Holanda, João Maurício, Conde de Nassau-Siegen, era uma proposta de definição de Estado e suas relações com a sociedade neerlandesa, com implicação direta para a inclusão de sua contraparte colonial em ambas as Índias, o que incluia o caso do Brasil.

A segunda atitude era encampada por grandes mercadores que, sobretudo sediados em Amsterdã, tinham investido na WIC, mas que após 1638 preferiram defender a posição econômica do livre comércio e a pauta política do republicanismo civil (WÄTJEN, [1938] 2004). Esse grupo passou a ser hegemônico depois da Paz de Münster, em 1648 e, sobretudo, depois da morte prematura de Willem II, em 1650. A instituição dessa posição republicana, civil e defensora do livre comércio, trouxe implicações para as relações entre o corpo político dos Vereenighde Nederlanden, Países Baixos Unidos, e a inclusão ou não nele do território e sociedade coloniais no Brasil. Essas implicações sociais estão imbricadas com a mudança do imaginário neerlandês sobre o Brasil e com a construção cultural de uma visão paisagística do Brasil em Frans Post.

O ano de 1649 pode ser tomado como o ano crucial para entender a mudança de atitudes neerlandesas acerca do Brasil holandês (MELLO, 2003, p. 195). Apesar de todo o clima de revolta, desencadeado pelas notícias sobre as derrotas nos Montes Guararapes, aparentemente só o Estado da Zelândia e o Estado de Groningen insistiam junto aos Estados Gerais dos Países Baixos Unidos para que estes interviessem diretamente em relação à questão militar no Brasil. Por sua vez, o Estado da Holanda se dividia: se, por um lado, a gemeente, comunidade civil, de Leiden e a de Haarlem, notoriamente orangistas 
(PRICE, 1994, pp. 66-67; ISRAEL, 1995, p. 601; MELLO, 2003, p. 67), eram a favor da pauta zelandesa e do partido da guerra; por outro, a comunidade de Amsterdã, dirigida por representantes ligados ao capital dos grandes mercadores e financistas, inimigos até da WIC (BOXER, [1957] 2004, p. 363; HOBOKEN, 1960, p. 46), tornara-se mais renitente quanto a investir financeiramente numa situação militar já então considerada dificílima de ser revertida. O que ficaria claro, alguns anos mais tarde, é que o partido da paz e seus interesses comerciais sobre os mercados ibéricos (como o sal de Setúbal e o tráfico de escravos africanos para o (aribe) terminaram por fazer Amsterdã pender a balança, desinteressando-se gradativamente pelo território ocupado pela WIC no litoral do atual nordeste do Brasil (BOXER, [1957] 2004, pp. 360-365; HOCHSTRASSER, 2007, p. 168).

Nesse mesmo ano de 1649, Frans Post executou duas pinturas, de dimensões idênticas, e de composições que se relacionavam simetricamente entre si, nas quais aparece um panorama de várzea. Trata-se de Paisagem com rio e tatu e Paisagem com rio e tamanduá, um par de painéis, em óleo sobre madeira, de $53 \times 69,4 \mathrm{~cm}$, hoje na Alte Pinakhotek, em Munique. No ano seguinte, em 1650, outra composição, apresentando o mesmo tema da vista panorâmica de várzea através de diferente tratamento ao tema, sugere um outro tipo de imagem ou uma outra forma de imaginar e visualizar a terra do Brasil. Trata-se de Paisagem com rio e índios, óleo sobre madeira, $61 \times 91,4 \mathrm{~cm}$, que se encontra n' The Metropolitan Museum of Art, em Nova Iorque.

Se compararmos o par de 1649 com o quadro de 1650, poderemos concordar com Ruud Joppien, quando, falando em geral das paisagens de Frans Post, sugerira a tentativa consciente (e portanto não-acidental ou arbitrária) desse em "[...] expressar, de fato, diferentes formas de paisagem por meio do contraste entre um tipo bucólico e arcádico e uma mais séria visão histórica" (JOPPIEN, 1979, p. 336).

Ao considerar as categorias de Joppien, diríamos então que, enquanto o par de 1649 representa a paisagem brasileira através da idealização de localidade fantasiada, o quadro de 1650 retoma uma imagem mais descritiva da geografia e etnografia do Brasil. A questão que aqui levantamos é a de saber se essas duas formas de representar as observações da terra do Brasil correspondiam a diferentes maneiras de imaginar o Brasil. Ou, dito de outro jeito, trata-se aqui de investigar se a cada estratégia visual correspondia 
um discurso acerca do Brasil. Definimos aqui estratégias visuais “[...] como a(s) escolha(s) de uma ou mais técnicas de representar o objeto observado com a finalidade de dar visibilidade a determinado aspecto desse último, com o que se quer chamar atenção com a imagem." (VIEIRA, 2013, p. 40).

A fim de poder dar sequência a esse estudo, foi necessária, primeiramente, uma comparação iconográfica entre o par de quadros de 1649 e o quadro de 1650 para estudar os motivos das figuras humanas e os tratamentos formais à paisagem, a fim de investigar a hipótese de que se tratou de duas estratégias visuais distintas.

Entretanto, esta história cultural da paisagem política do Brasil holandês em Frans Post não deve ser entendida como a proposição de que devemos investigar sua imagem única e exclusivamente do lugar da disciplina histórica. Muito pelo contrário. Outros saberes, sobretudo a história da arte, podem e devem se debruçar sobre o estudo da produção e recepção de sua imagem.

Escolhemos a disciplina histórica para abordar sua imagem por conta da natureza do nosso objeto de estudo: o imaginário social do Brasil na cultura visual neerlandesa do século XVII. Ademais, nesse sentido, acreditamos poder ampliar uma interface de estudos em duas áreas: a da imagem e a da história. Assim, tratamos de demonstrar que há elementos presentes na imagem de Post que são sociais, oriundos do fazer histórico. 0 privilegiar desse viés não implica, por um lado, no fato de que se devem abandonar outras acepções que a imagem permite sondar; mas, por outro, demonstra que é possível localizar aqueles elementos do fazer histórico, através do exame dos vestígios deixados pelo processo social de fabricação da própria imagem. Longe de querer explicar a imagem unicamente pelo contexto histórico, propomos apenas que esse é uma instância que, sendo localizada na imagem, faz dessa um objeto de estudos das ciências humanas. Neste sentido, ao conceber a imagem de Frans Post como documento iconográfico, portador de vestígios visuais que apontam para imaginários sociais contemporâneos a sua própria construção cultural, estamos sugerindo que é possível que se proceda a uma investigação histórica a partir do uso de imagens. 
Comecemos pelo quadro de 1650. A antecipação cronológica pode ser justificada por se tratar de recorrência a uma primeira forma de construir uma imagem do Brasil. Examinemos, agora, os elementos que compõem essa estratégia visual para, mais adiante, considerar sua recorrência.

Os motivos em Paisagem com rio e índios guardam muita semelhança com os de Mocambos, quadro executado quatro anos antes. Mas, ao contrário desse último, naquele, os elementos arquitetônicos foram diminuídos e recuados na distância, como no exemplo dos telhados, sugerindo casas de taipa em meio à mata, no plano médio e à esquerda. A abrangência panorâmica do território ganha mais destaque tanto quantitativamente, nas dimensões que ocupa na superfície do painel; quanto qualitativamente, pela centralidade do tema no todo da figuração.

Há um grupo de indígenas, situado à beira de um caminho, na encosta de uma colina. Guerreiros tupis, eles aparecem com suas lanças, parcialmente escondidos, por trás dos arbustos que formam o repoussoir, à direita da composição. O detalhamento das roupas e utensílios, bem como a maneira de carregar os bebês e os cestos, apontam para a mesma exploração do impulso etnográfico tal qual em Mocambos. O elemento descritivo dessa etnografia, no entanto, não significa que se tratasse da apresentação imparcial do Outro. A representação das figuras humanas e a disposição de seus corpos sugerem uma relação iconográfica com os "retratos etnográficos" feitos por Albert Eckhout (BRIENEN, 2006; MASON, 1998). Antes, essa semelhança aponta para um tratamento específico: a pose, sobretudo a pose frontal da índia à direita e a da mameluca, à esquerda. Entre elas, as mulheres e as crianças do grupo. Já a disposição dos guerreiros, enfileirados uns ao lado dos outros, parece evocar o motivo central de Dança dos Tapuias, outro quadro que Albert Eckhout compusera no tempo em que João Maurício, Conde de Nassau-Siegen, tinha sido Governador-geral do Brasil holandês.

O recurso à pose denuncia que a representação das figuras humanas não se referia a indivíduos, cada uma correspondendo a uma pessoa singular. A ênfase recai no grupo, sugerindo que as figuras correspondem antes a tipos. Assim, ao invés de mera descrição etnográfica, a representação do grupo é uma tipificação, tirada das referências a uma hierarquização eurocêntrica do não europeu. O impulso etnográfico na descrição 
holandesa do tupi se conformou a uma estruturação do Outro através de acomodações que o tornavam familiar, através de analogias que denotavam uma hierarquização etnocêntrica (VIEIRA, 2012). Podemos afirmar que esse processo foi a construção do típico, a partir da instituição de atributos, a fim de operar a assimilação cultural do tupi à ordem social que os holandeses criavam no Brasil colonial. A inclusão de objetos etnográficos observados empiricamente corroborava a naturalidade do ato de tomar o tupi como um tipo, numa atitude que, independentemente de consciência ou não, era já o enquadrar do Outro em categorias europeias. Nesse sentido, a descrição quer-se isenta de juízo de valor, mas, na verdade, estava longe disso.

Ao fundo, o olhar do observador, descendo as colinas, se depara com os meandros de um curso d'água. Na outra margem, o terreno volta a se elevar. No centro da composição, silhuetados contra o céu cinza, uma fileira de coqueiros se sobressai em meio à vegetação e à topografia. À esquerda, o terreno perde altitude, parecendo se aplainar em várzea ou restinga, para voltar a se erguer em colinas só bem próximo à linha do horizonte, e ainda assim, apenas numa tênue sugestão.

Três aspectos dessa composição sugerem uma continuidade no uso da estratégia visual de representar o território observado tal como nas imagens nassovianas do Brasil holandês. O primeiro deles se refere às dimensões do quadro, que apesar do suporte de madeira, são muito próximas das telas conhecidas do período de 1637 a 1640. Isso pode indicar o fato de que o comprador do quadro podia ser familiarizado com os quadros da série nassoviana. Não há evidências, porém, de que se trata de alguém que os viu na corte de Vrijburg, na Cidade Maurícia, uma vez que a série, ou parte dela, deve ter sido exibida, ao menos temporariamente, na própria Mauritshuis, o palácio que João Maurício construíra em Haia.

O segundo e terceiro aspectos se relacionam com o tratamento dado ao tema e reforçam a hipótese aqui de que se trata de uma visão do Brasil em consonância com as imagens nassovianas. Primeiramente, o céu. Após quatro quadros em que Frans Post experimentou novos tons de azuis, em Paisagem com rio e índios, o céu volta a ser representado em cinza, sugerindo o ar carregado e úmido de um dia nublado de inverno, tal como nos quadros pintados no Brasil. Porém, finalmente, o aspecto mais contundente 
dessa estratégia visual consiste no uso de marcos paisagísticos, reconhecíveis a distância, e identificadores de localidades oficiais do Brasil holandês. No caso aqui, os coqueiros na linha do horizonte. Por comparação ao plano de fundo de Vista de Itamaracá, quadro de 1637, executado logo que Post chegara ao Brasil, é possível reconhecer os coqueiros do terreiro que está situado no alto da colina onde se assenta a Vila de Nossa Senhora da Conceição, conhecida no Brasil holandês por Schkoppestadt, na margem norte do Canal de Santa Cruz, já na ilha de Itamaracá.

Frans Post já havia representado os tais coqueiros de Vila Velha (como hoje se chama a localidade), a distância, no desenho de 1645, sobre Igarassu (BARLAEUS [1647] 1980), com o objetivo de relacionar as duas localidades na relação com a cartografia do Brasil holandês. Nunca é tarde para relembrar que, no livro de Barlaeus, a cada prancha contendo uma vista de perfil, correspondia um mapa local. Ao observador ciente de que os coqueiros assinalavam o lugar de Vila Velha, ao olhar a gravura de Igarassu, podia-se aferir que esta ficava a sudoeste daquela.

Tal operação visual não era novidade para o público neerlandês, familiarizado tanto com impressos contendo vistas topográficas quanto com mapas. As gravuras de Esaias van den Velde, com motivos tirados dos arredores de Haarlem da década de 1610, por exemplo, parecem sugerir, ao observador, pistas visuais para a localização do sítio representado. Spaarnwoude, por exemplo, é uma localidade próxima à cidade de Haarlem, e que, tendo sido palco de manobras militares durante o cerco espanhol a Haarlem, em 1573, tornou-se um tema que articulava paisagem e história nas gravuras de Esaias van den Velde nos anos 1615 e 1616. Em uma das gravuras de Van den Velde, se vê a distância e à esquerda, a Grote Kerk, a Igreja Grande, de Haarlem. Em outra imagem da mesma série, de um canal congelado, o ponto de vista é remontado agora na relação com a própria torre da igreja de Spaarnwoude que, alta e estreita, se vê à distância (GROOT, 1954-1979; LEVESQUE, 1994). Essas triangulações, possibilitadas pela inclusão dos mesmos marcos de referências em duas ou mais gravuras numa mesma série, permitiam ao espectador que construísse uma imagem mental das localidades e de suas relações espaciais a fim de, constituindo-as em lugares históricos, dar sentido à paisagem por meio de uma noção geográfica. 
Assim, os coqueiros de Paisagem com rio e índios funcionam como marcos que orientam as direções geográficas de forma a sugerir ao observador dois aspectos importantes. Primeiramente, que havia uma continuidade entre o sítio representado e o sítio observado. Apesar da manipulação da observação, que conferiu visibilidade aos coqueiros, ao "trazê-los" mais para o centro, "tirando-os" de detrás da colina, posição que, embora fosse mais condizente com o ponto de vista construído pela imagem, inviabilizaria o uso do marco paisagístico. Em segundo lugar, essa descriptio geográfica era a contrapartida da descrição etnográfica dada ao motivo das figuras humanas: descrição dos tupis e localização do Brasil no imaginário neerlandês. Frans Post quis situar a cena em algum lugar a sudeste de Vila Velha, mas fazendo alusão direta a ela e aos filhos da terra. Dessa forma, o que era só um rio em curva, torna-se de fato em sua imagem a foz do rio Igarassu, no seu encontro com o Canal de Santa Cruz.

É importante deixar claro, entretanto, que não estamos sugerindo aqui que o uso dessa estratégia (de associar o representado à referência de uma localidade específica) fosse simplesmente o utilitarismo cartográfico. Não se trata de reduzir a paisagística a uma característica "map alike”. O ponto central aqui nesta análise é o de demonstrar que uma tal imagem da terra do Brasil foi construída com empréstimos de uma descriptio geográfica que, ao incluir o Brasil numa cosmografia neerlandesa do globo, poderia provocar no observador um orgulho pátrio. Embora isso se desse por inversão colonial: não o sentimento identitário de pertença a Haarlem ou à Holanda; mas o orgulho de ver aquele pedaço específico de uma terra longínqua como o Brasil enquanto parte integrante das possessões ultramarinas dos Países Baixos Unidos.

Porém, antes de avançar nessas implicações políticas de colonialidade, devemos voltar ao ano de 1649, quando Frans Post executou o par Paisagem com rio e tatu e Paisagem com rio e tamanduá.

Em ambos os quadros, podemos reconhecer diversos motivos e tratamentos que Post vinha testando em seus primeiros anos de atividade na Holanda. A começar pelo céu, mais azul. Repetido de Cachoeira de Paulo Afonso no par de 1649, o céu azul confere à paisagem brasileira um aspecto mais radiante do que nos tons invernais das telas anteriores a 1644. Mas também no uso de espécies botânicas e zoológicas em tratamento 
pormenorizado que compõem um repoussoir do alto à esquerda a toda parte inferior do primeiro plano do primeiro quadro, completando-se da parte inferior de todo o primeiro plano até o alto à direita do segundo quadro. Ampliando o uso da fórmula desenvolvida na composição do quadro Sacrifício de Manoá, executado no ano anterior, em 1648, Frans Post compôs uma única e imensa paisagem panorâmica em dois quadros. Mamoeiro, mandacaru, nhambu-guaçu, pino e caraguatá acompanham o tatu; enquanto o ananás, pino, cabaça, bananeira e pindoba se somam ao tamanduá (FERRÃO; SOARES, 1993). Comparando esses elementos com o repoussoir de Sacrifício de Manoá, vemos que Post separou as espécies maiores, mandacaru e mamoeiro à esquerda e bananeira à direita, reforçada em seu efeito de "panorama wing" pela pindoba. ${ }^{2}$ Ademais, situou as bromeliáceas estrategicamente em justaposição ao plano médio, como o caraguatá na brecha por entre a vegetação da mata, enquanto o tom do amarelo do ananás foi realçado contra o azul prata do céu refletido na superfície da água. Eis o "cortinado" dessa paisagem teatralizada, fiado com as tramas da naturalia brasiliana.

Em Paisagem com rio e tatu, um grupo, composto por índios tupis, e relativamente numeroso, percorre o caminho. Mais a distância, uma mucama segue à frente de outros escravos, que levam a senhora em uma liteira. Provavelmente desembarcaram da chalupa que subiu o rio e estão se dirigindo às edificações que sugerem uma povoação formada em torno de um ou dois engenhos de açúcar. A margem oposta, depois da curva do rio, apresenta uma colina tomada pela vegetação da mata atlântica. Ao fundo, o rio serpenteia pela várzea, em meio à mata ciliar e aos campos, na direção do oceano.

No seu pendant, Paisagem com rio e tamanduá, as figuras humanas são menos numerosas, mas estão representadas em proporções e dimensões idênticas às do primeiro quadro. Aqui não há barcos. O transporte é feito pela estrada: o senhor, montado num cavalo, à frente, os escravos trazendo a senhora na liteira, e uma mucama atrás, trazendo um cesto à cabeça. O motivo da dama carregada por escravos em uma liteira, ou palanquim, já ocorrera no desenho Forte Príncipe Guilherme, de 1645, que Post fizera para as pranchas do livro de Caspar Barlaeus e mesmo em uma das vignetas do mapa mural de Georg Marcgraf. Ele parece ter sido uma fórmula de descrição de

\footnotetext{
2 Para o conceito de "Panorama Wing”, cf. STECHOW, 1966.
} 
costumes portugueses bem presente na cultura visual neerlandesa desde, pelo menos, os Ícones de Jan Huygen van Linschoten (BOOGAART, 2003). O pequeno grupo parece margear o rio na direção da casa-grande. Menos povoado, o lugar apresenta apenas dois engenhos: um de baixo, próximo à margem do rio; outro de cima, no alto da colina.

Consideremos essa estrutura de composição e comparemo-la com a do quadro de 1650, a partir de dois motivos na paisagem: as figuras humanas e o terreno.

Já vimos que a manipulação do observado no quadro de 1650 serviu para Post construir uma imagem do Brasil que estava relacionada ao discurso geográfico e etnográfico. Já as figuras humanas do par de 1649 não trazem esse mesmo tratamento. Elas não posam, nem estão posicionadas mais de perto, como que se deixando ser observadas. Antes, sua aparência ao natural não se limita ao próprio motivo, mas expande sua relação com o entorno da paisagem. Aqui o realismo anacrônico da crítica do século XX conferiu a uma tal estratégia visual a noção de "instantâneo", considerando esses elementos como índices de um real visto. Mas isso deve ser entendido muito mais como reprodução de um discurso mimético da segunda metade do oitocentos sobre a fotografia e tornado em teoria da imagem. Se elas, essas figuras humanas nos quadros de 1649, dando as costas ao observador, parecem naturalmente inseridas na paisagem "real”, é porque elas estão imersas numa "realidade" que é a delas. Elas agem como personagens num cenário; elas representam num mundo cuja natureza é a própria representação, como no desenrolar de um drama em um palco.

Segundo o anacronismo da crítica acima mencionada, a perda da originalidade, nas imagens que Frans Post criou para o mercado de arte, já de volta a sua Haarlem natal, foi formulada nos termos de um afastamento do "idioma" visual em relação à verossimilhança fotográfica. Informada por uma noção positivista da História, essa crítica considerou a produção de Frans Post, posterior a 1645, como não documental. Ou antes, e mais especificamente, se os motivos ainda eram tratados "realisticamente", o todo da composição passou a ganhar um sentido mais ficcional.

Assim, todo um léxico ligado à ficção, invenção e criação, foi contraposto à noção documental da realidade brasileira da primeira fase, para ser aplicado ao conjunto 
posterior da obra de Post e justificado pelo fato de que foi produzido longe do Brasil, tanto no espaço quanto no tempo. Do naer 't leven, ao natural, da documentação visual in loco, passou-se ao uyt den gheest, criação do espírito, comportando inclusive as falhas da memória.

Essa dicotomização entre documentação e ficção na imagem de Frans Post está baseada em premissas anacrônicas. A relação entre "ficção" e "realidade" nas primeiras imagens de Post não é de antagonismo. Para fixar ou registrar uma observação empírica em imagem é necessário todo um processo de criação que implica na edição (seleção, manipulação, arte-finalização) dos próprios estímulos perceptivos. A construção imaginária da realidade comporta um processo ficcional.

Problematizar a relação entre "ficção" e "realidade" na obra de Frans Post (abolindo a dicotomia entre as duas categorias sem, no entanto, ir ao extremo oposto de amalgamá-las; ou seja, distinguindo-as em suas especificidades ainda que concebendo-as como inter-relacionadas) é investigá-la a partir de um sistema de valores, sentidos e significados construídos no contexto específico de sua própria cultura visual (DIKOVITSKAYA, 2006).

O "real" ou a "realidade" não devem ser categorias contrapostas à "ficção" ou ao “imaginário”. A realidade é ficcional e imaginária, embora nem toda ficção e nem todo imaginário nos remetam ao que é empírico, mas, atravessando a fronteira entre o tangível e o intangível, termina por adquirir uma condição daquilo que podemos chamar de fantástico; mas, o empírico e o fantástico se entrelaçam na ficção imaginária do real.

É evidente que a suposta “descrição" etnográfica e geográfica do quadro de 1650 é também uma representação. Entretanto, as figuras dos quadros de 1649 são parte de um tipo de imagem diferente: não uma representação que precise se remeter metonimicamente a um "algo", exterior, a priori; mas uma representação cuja realidade é a própria ontologia de sua trama ficcional. E essa teatralidade era a simulação que punha em movimento as peças da wonderkamer, o gabinete de curiosidades. Sugestão essa de movimento que instaurava uma temporalidade narrativa entre as figuras humanas e a paisagem. Ali vão o senhor montado e sua senhora, carregada na liteira pelos dois 
escravos, visitar parentes ou amigos. Ou voltam à casa-grande de seu engenho, vindos da cidade, onde o senhor fora cuidar de seus negócios. Essa narratividade engaja o observador nesse processo de simular o movimento dos atores em cena, mas ao teatralizar essa representação, termina por segregar o próprio observador para fora do cortinado. Como espectador, ele vê o mundo dos trópicos como um voyeur, a distância.

Portanto, podemos afirmar que o par de 1649 e o quadro de 1650 são ambos realistas e ficcionais, embora cada um a sua maneira. Tanto os primeiros quanto o segundo são ficcionais na medida em que selecionam e editam as observações empíricas de forma a representarem-nas enquanto realidade. Em ambas encontramos uma manipulação do observado. A diferença entre elas reside, no entanto, nas diferentes estratégias visuais escolhidas por Post de acordo com distintas convenções, de forma a enfatizar variadas atitudes em relação à terra do Brasil. Não cabe aqui perguntar se a paisagem em Frans Post corresponde a esta ou àquela estratégia visual. Mais relevante é reconhecer a ambiguidade conceitual da imagem paisagística.

A landschap schilderij, pintura de paisagem, como compreendida pela cultura visual dos Países Baixos do século XVII, pode ser descrita como um dispositivo que surgiu na confluência entre uma formação discursiva residual, relacionada à noção de domínio e soberania do corpo político, e uma formação discursiva recentemente emergida na história do Ocidente, relacionada à espacialidade figurativa na representação visual (VIEIRA, 2013). Os neerlandeses do início da Idade Moderna estavam cônscios de que a paisagem era uma categoria que podia ser aplicada tanto a imagens e a mapas quanto a sítios, como atestam seus conhecimentos sobre os autores clássicos, dentre os quais Cícero, Lívio, e Plínio, o Moço, que escreveram sobre a experiência de olhar o campo (MELION, 1991, p. 175).

Assim, a paisagem poderia ser mobilizada pela cultura visual neerlandesa de então para provocar diversas respostas do observador, a depender do que se queria com a imagem: por meio da exortação poética, construir visualmente uma cena e locação fantásticas, ou se utilizar das mesmas capacidades ficcionais para fixar em imagem uma vista específica de lugar, mobilizando a imaginação para visualizar o caso particular relativo às coisas visíveis. Eis a ficção paisagística a serviço da topografia. O próprio Karel 
van Mander (1969 [1604]) assim o confirma. Em seu livro, Het Schilder-Boeck, O Livro do Pintor, sobre as vidas dos pintores neerlandeses, publicado em 1604, no fim do capítulo quinto, "Van der Ordinanty ende Inventy der Historien", da ordenança e da invenção das histórias, ele sugere que o artista poderia fazer como Parrásio havia feito nos dias antigos, representando Atenas. Comentando também que Roma havia sido tema de representação pelos antigos, Van Mander (1969 [1604]) incluiu na arte da pintura o tema da representação de sítios e lugares, em um texto que serviu de base teórica para a construção dos cânones artísticos que legitimaram a pintura de paisagem no início do século XVII.

Assim, antes de confinada entre duas polaridades antagônicas, a paisagem era a possibilidade do interregno. Cartografia de convenções e códigos de representação; mas também narrativa teatral que se apoiava numa densidade discursiva/imagética que só a observação empírica podia fornecer.

Nesse sentido, harmonizando dois tipos de imagens sobre o Brasil, Frans Post pode fazer uma dupla operação: primeiramente, ao inserir figuras humanas consideradas típicas juntamente com marcos paisagísticos em suas cenas, ele forneceu elementos de exortação poética a partir de representações de lugares do Brasil holandês; e em segundo lugar, retirando os marcos paisagísticos e aumentando a manipulação do sítio observado, mas sem substituir as figuras típicas do Brasil por figuras que aludissem a passagens clássicas ou bíblicas, estava ele circunscrevendo uma paisagem de amenidades aos quadros da geografia brasiliana.

Assim, a índia à esquerda e os coqueiros distantes, no centro, funcionam, no quadro de 1650, como convenção etnográfica e marco paisagístico, respectivamente, de modo a relacionar geograficamente a paisagem à experiência visual de alguém que estivesse nas colinas a leste do ponto em que o rio Igarassu deságua no Canal de Santa Cruz, defronte aos coqueiros de Vila Velha. Não em qualquer outra coordenada do globo, mas só e somente naquele ponto singular.

Por outro lado, o cenário dos quadros de 1649 traz muita densidade de informação visual sobre a experiência de lugar, ainda que não remetesse a nenhuma coordenada 
específica. Era Frans Post adequando seu repertório de observações a serviço de uma outra imagem. Uma imagem que modificava seu próprio objeto: não a vista de Vila Velha, mas a visualização de um lugar imaginado, embora essa imaginação se apresentasse verossímil para um observador familiarizado com os lugares do Brasil holandês. Se não se referia a uma localidade específica, tampouco era uma impossibilidade; antes, era um lugar hipoteticamente localizável. Tanto que podemos relacionar os elementos da descrição paisagística, reunidos ainda que de forma idealizada no todo da composição, à zona de transição, que são as várzeas dos rios da Zona da Mata pernambucana, entre as restingas do litoral e os morros de massapê, contrafortes mais ao leste e primeiros degraus que são, suaves ainda, do Planalto da Borborema.

Mais especificamente ainda, podemos aferir, pela forma arredondada dos morros, se tratar da Zona da Mata Sul. Ao norte da várzea do Capibaribe, o terreno, que a mais ou menos dez quilômetros da costa se eleva a 100 metros de altitude, conforma-se nos chamados "tabuleiros", plateaux de baixa altitude. Porém, ao sul do Capibaribe, a topografia se ergue na forma de morros sucessivos e arredondados, tal como vemos nos municípios do Cabo de Santo Agostinho, Ipojuca e Sirinhaém. Todas localidades visitadas por Frans Post e que, juntamente com a várzea do Capibaribe, constituíam o cerne da lavoura canavieira do Brasil holandês. Após a Insurreição Pernambucana de 1645, os portugueses abandonaram os assentamentos do norte de Pernambuco, e das capitanias de Itamaracá, Paraíba e Rio Grande do Norte, para se fixar na Zona da Mata sulpernambucana, da Várzea do Capibaribe a Porto Calvo. Essa manobra militar limitava o perímetro a ser defendido, mas também demonstrava a escolha em permanecer no setor mais produtivo do açúcar. Os holandeses também deviam reconhecer esse fato pois, em 1654, rechaçaram a proposta do embaixador português em Haia, que propunha devolver o território ao norte do Capibaribe a WIC, por deixá-los sem o coração da colônia açucareira (MELLO, 2003, pp. 121 e 206).

O terreno e sua disposição, recebendo a umidade atlântica, contribuíam para a fertilidade do solo e tornavam essas várzeas as mais produtivas do território em disputa entre portugueses e neerlandeses. Sobre o assunto, afirmou Joan Nieuhof, que viveu no Brasil durante praticamente toda a década de 1640: 
Todo o litoral brasileiro está literalmente tarjado de pequenos cursos d'água que se vêm lançar ao mar após terem banhado extensos vales. Por isso os engenhos de cana erigidos nas regiões ribeirinhas desfrutam grande economia tanto no transporte como na mão-de-obra. Além de moverem, esses rios, os engenhos instalados em suas margens, servem eles para o transporte do açúcar e constituem via fácil para o abastecimento das usinas. Condições assim tão vantajosas, não se encontram em nenhum outro país das Índias Ocidentais, e, por isso, neles não se poderia cuidar com lucro da cultura da cana (NIEUHOF, [1682] 1981, p. 95).

Da mesma maneira como podemos apreender, na passagem de Nieuhof, a preocupação em valorizar essa área para não perdê-la (lembremos que em 1649 não fazia muito tempo que os insucessos dos Guararapes tornaram o Brasil holandês um investimento duvidoso), é possível relacionar a organização visual nesse par de quadros de Post ao clima de interesses econômicos e decisões políticas sobre a manutenção da ocupação do Brasil e dos interesses açucareiros.

O texto de Nieuhof demonstra que a descrição geográfica podia ter o cunho utilitarista da propaganda econômica. Essa geografia pragmática não precisava, por exemplo, operar por referência específica ou por localização. Usar o conhecimento de que o vale e a várzea do rio Sirinhaém eram fecundos a fim de afirmar que a terra do Brasil era a mais indicada para a instalação da lavoura canavieira e dos engenhos de açúcar não é a mesma coisa de singularizar Sirinhaém em heráldica oficial, conferindo ao lugar uma importância política a partir dos quadros das possessões dos Países Baixos Unidos. Da mesma maneira, o modo de topografia oficial de localidades, reconhecíveis pelos brasões, mas também visíveis na inscrição de marcos paisagísticos e com implicações para uma visão corográfica do Brasil holandês, foi abandonado por Frans Post quando esse tratou de compor imagens da atividade açucareira no Brasil holandês.

Assim, toda a gama de observações que ele fizera foi canalizada para compor um todo que era idealizado, embora com elementos visualmente convincentes. O par de quadros de 1649, somadas suas dimensões horizontais ao compor um todo, era a eloquência visual de um panorama de 180 graus que, situando o observador num ponto 
hipotético (a curva de nível que marca a linha de inflexão entre a área da várzea e a área dos morros), sugeria alegoricamente todo o cenário da colônia açucareira: ao centro, a baixada do rio em direção ao mar; à esquerda, na direção norte, a margem do rio Capibaribe e, para além dela, o "mattam do Brasil” (em alusão à mata atlântica); e à direita, na direção sul, os morros ficando cada vez mais altos depois do rio Ipojuca, na direção dos Palmares. Nos anos de 1640, em que Phillips Koninck pintava extensos panoramas, Post pode ter usado tal fórmula como referência convencional para montar sua cena: uma paisagem nos moldes da holandesa, apenas mais arredondada nas formas brasileiras, como na sugestão de Ruud Joppien (1979, p. 335). Para esse autor, essa resultante na imagem de Frans Post era a adaptação de uma imagem posta a representar a fertilidade da terra do Brasil (Idem, p. 336). Porém, ao mobilizar um repertório visual de alteridade, ${ }^{3}$ perpassado por códigos de representação de terra estrangeira, essa estratégia visual evitava a vinculação entre paisagem e corpo político de soberania pátria.

Podemos ainda remontar a potência de tal imagem em seduzir o público neerlandês desejoso de imagens do Brasil, se levarmos em conta um aspecto duplo, que perpassou sua produção na inter-relação com sua recepção. Primeiramente, a simplificação e idealização, ainda que usando o típico como simbologia tropical inscrita na convenção paisagística neerlandesa (o tatu enquanto alegoria da América, a palmeira em alusão aos trópicos, etc.), contornavam o problema da referência distante. Para um público que mal sabia que a cachoeira de Paulo Afonso era o ponto extremo de um território cujo centro de gravidade era o Recife, Frans Post deve ter precisado rever a forma de organizar e editar visualmente suas observações. Seria inútil insistir na distinção visual entre a várzea do Ipojuca e a do Sirinhaém, pois isso não devia importar para seu público consumidor. A não ser para aqueles defensores de uma imagem nassoviana do Brasil, em relação estreita com o orangismo do partido da guerra. Mas o que devia importar nessas imagens idealizadas, tendendo para a indiscriminação dos lugares coloniais, dos sítios oficiais, devia ser a referência ao açúcar e a sugestão de riqueza que dele se evocava. O público consumidor de tais cenas, supostamente brasílicas, devia estar mais relacionado ao republicanismo civil dos regentes de Amsterdã, e, portanto, mais

\footnotetext{
${ }^{3}$ Para a noção de vocabulário visual de alteridade, cf. GOEDDE, 1989; e SPICER, 1998.
} 
interessado nos lucros advindos do livre comércio com os Trópicos do que disposto a financiar uma guerra de altos custos para a ocupação de um território colonial distante, ainda que numa posição geopolítica estratégica para todo o Atlântico.

No entanto, se essa fórmula (síntese resultante do embate entre o naer 't leven, ao natural, das observações de Frans Post nos trópicos brasileiros e os códigos e convenções de representação de terra estrangeira na paisagística neerlandesa) fez tanto sucesso, a ponto de se repetir numerosamente ao longo da sua promissora carreira profissional (LAGO, 2006, p. 124), resta-nos a questão de se saber o porquê do retorno à fórmula corográfica de uma imagem etnográfica e geográfica como a do quadro de 1650, uma vez que a sabemos diretamente relacionada ao uso oficial e ao discurso orangista-nassoviano para o Brasil.

A crítica tem sugerido a hipótese de que essas imagens, mais "realistas", eram para um público que Post conhecera ainda no Brasil e que, de volta à Holanda, tornaramse seus prováveis compradores. Por outro lado, as outras imagens, mais "fictícias", seriam a conquista de um público mais amplo, à medida que ele se estabelecia no mercado de paisagens como pintor do Brasil. A força sugestiva de tal argumento reside não na proposta de decifrar o problema da "referência distante", mas justamente no chamar a atenção para o problema. Só que o problema não é tão simples assim. Relativizemos um pouco a questão dos conhecimentos geográficos prévios de Post como elementos enriquecedores do exercício de ver suas imagens.

Um comerciante holandês sediado no Recife não necessariamente podia discernir a diferença no aspecto visual de São Miguel de Ipojuca, de um lado, e São Roque de Sirinhaém, do outro. Uma vez que a produção açucareira permanecera uma atividade de portugueses e mazombos (portugueses filhos da terra do Brasil), e o comércio podia ser controlado desde a alfândega no Porto do Recife, os mais prováveis candidatos a tal conhecimento geográfico eram porventura oficiais do exército e funcionários da administração. Por outro lado, nos Países Baixos, era possível a um público que não tinha estado no Brasil, mas familiarizado com a cartografia, a literatura de viagens e à produção nassoviana sobre o Brasil, obter um mínimo de referências com as quais poderiam se engajar na corografia oficial. 
Portanto, o conhecimento geográfico sobre o Brasil, ou a falta dele, na relação direta com a referência distante ao objeto da produção de Post não era necessariamente um critério para apreender quem seria(m) o(s) seu(s) possível(eis) público(s) consumidor(es). Antes, o viemos argumentando até aqui, é que mais importantes teriam sido os interesses comerciais e políticos, oriundos dos particularismos culturais neerlandeses, e que possibilitavam os quadros sociais nos quais se inscreveram as expectativas e atitudes sobre o Brasil. Enquanto, por um lado, imagens mais idealizadas da várzea açucareira poderiam encontrar compradores que se interessavam pelo livre comércio do açúcar; por outro, imagens que operavam pela localização geográfica podiam achar seu caminho a um público que, sendo investidores da WIC, mas sem capital suficiente para vencer a livre-concorrência, dependiam dos Estados Gerais para, mantendo a possessão brasileira, ter acesso a seus produtos, como era notório em relação aos grupos zelandeses.

É possível, portanto, que Frans Post tivesse clientes ligados à Câmara de Amsterdã e à Câmara da Zelândia, sendo Haarlem, sua cidade natal, um microcosmo desse embate entre republicanismo liberal e intervencionismo orangista, oferecendo a Frans Post uma clientela dividida entre esses dois públicos.

Parte do capital investido na WIC pela câmara de Amsterdã vinha de fora, inclusive de Haarlem, o que pode ser um indício de um público local mais interessado no comércio açucareiro (EMMER, 1998, p. 67). Dos 2.846.520 de florins computados como o capital inicial levantado pela Câmara de Amsterdã à WIC, 134.150 florins foram da responsabilidade de Haarlem (ISRAEL, 1989, p. 159). Isso fazia com que Haarlem tivesse direito à representação na Câmara de Amsterdã (DEN HEIJER, 2003, p. 82). No entanto, supomos que esse capital fosse apenas em parte oriundo de outras atividades econômicas em Haarlem, e não necessariamente todo ligado ao comércio e refino do açúcar.

Se a consideração feita acima estiver correta, então há sentido em levantar a hipótese de que esses grupos poderiam ter, vendo nos mercadores de Amsterdã adversários de finanças, apoiado a causa de Orange, que procurava apoio justamente entre outras partes para contrapor-se a Amsterdã nos Estados da Holanda, como sugeriu 
J. L. Price (1994, p. 154). Para esse autor, “[...] Leiden e Haarlem ganharam, e muito mereceram, uma reputação pelo orangismo firme que durou por mais do que o resto do século após seus governos terem sido mudados na wetsverzettingen, a mudança do legislativo, de 1618. [...] (PRICE, 1994, p. 160)"

Ademais, essa posição orangista de Haarlem era reforçada pelos interesses econômicos específicos dessa, sendo ela uma cidade produtora, o que a colocava como antagonista de Amsterdã, cuja ênfase econômica estava no comércio, fazendo com que a primeira voltasse seus objetivos políticos para a direção do stadhouder (PRICE, 1994, p. 180).

Esse vínculo orangista pode ser verificado não só no plano municipal, mas também na própria biografia de Frans Post, uma vez que seu irmão (e provável mentor intelectual), Pieter Post, era "arquiteto ordinário dos Oranges" (SOUSA-LEÃO, 1973, p. 19). No entanto, pintando para o mercado e não mais para um nobre ligado diretamente à Casa de Orange, Frans Post deve ter precisado matizar sua criação paisagística de acordo com as duas posições encontradas em sua cidade natal, e mesmo estendidas à Zelândia, de um lado, e a Amsterdã, de outro: de um lado, a posição orangista-nassoviana do partido da guerra, defensora da manutenção do Brasil; e, de outro, o republicanismo do partido da paz, interessado no restabelecimento do livre comércio com os ibéricos.

A hipótese aqui é a de que, enquanto um discurso mercantil encontrava visibilidade nas cenas de paisagens indiscriminadas, em que a ênfase era mais no açúcar do que no território brasileiro; um outro, orangista, tinha sua visibilidade numa imagem cuja especificidade estava relacionada ao projeto colonial, apoiado numa geografia do Brasil, para propor a manutenção do território.

\section{Referências}

BARLAEUS, Caspar. História dos feitos recentemente praticados durante oito anos no

Brasil. Recife: Fundação Cultura Cidade do Recife, 1980. Tradução do livro de Caspar Barlaeus, Rerum per octennium in Brasilia..., Amstelodami, ex Typographeio loannis Blaeu, MDCXLVII. 
BOOGAART, Ernst van den. Civil and corrupt Asia: Image and Text in the Itinerario and the Icones of Jan Huygen van Linschoten. Chicago: The University of Chicago Press, 2003.

BOOGAART, Ernst van den. Realismo pictórico e Nação: as pinturas brasileiras de Frans Post in: TOSTES, Vera Lúcia Bottrel e BENCHETRIT, Sarah Fassa (orgs.) A presença holandesa no Brasil: memória e imaginário. Livro do Seminário Internacional. Rio de Janeiro: Livros do Museu Histórico Nacional, 2004.

BOXER, Charles. Os Holandeses no Brasil (1624-1654). [1957]. Recife: Companhia Editora de Pernambuco, 2004.

BRIENEN, Rebecca Parker. Visions of savage paradise. Albert Eckhout, court painter in colonial Dutch Brazil. Amsterdam: Amsterdam University Press, 2006.

BURKE, Peter. Testemunha ocular: história e imagem. Bauru: EDUSC, 2004.

DEN HEIJER, Henk. The Dutch West India Company, 1621-1791 in: POSTMA, Johannes; ENTHOVEN, Victor (Eds.) Riches from Atlantic Commerce: Dutch transatlantic trade and shipping, 1585-1817. Leiden / Boston: Brill, 2003.

DIKOVITSKAYA, Margaret. Visual culture: the study of the visual after the cultural turn. Cambridge, MA, The MIT Press, 2006.

EMMER, Pieter. The West India Company, 1621-1791: Dutch or Atlantic? In EMMER, Pieter. The Dutch in the Atlantic Economy, 1580-1880: trade, slavery and emancipation. Farnham: Ashgate Publishing, 1998.

FREEDBERG, David. Ciência, Comércio e Arte in: HERKENHOFF, Paulo (org.). O Brasil e os Holandeses, 1630-1654. Rio de Janeiro: Sextante Artes, 1999.

FERRÃO, Cristina; SOARES, José Paulo Monteiro (Eds.). Theatrum rerum naturalium brasiliae. Brasil Holandês / Dutch Brazil. Petrópolis: Editora Index, 1993. 2 vols.

GOEDDE, Lawrence Otto. Tempest and shipwreck in Dutch and Flemish art: convention, rhetoric, and interpretation. University Park: The Pennsylvania State University Press, 1989.

GROOT, Irene de. Landscape etchings by the Dutch masters of the seventeenth century. The Hague: Lummus Nederland B.V., 1954-1979.

HOBOKEN, W. J. van. The Dutch West India Company: the political background of its rise and decline in BROMLEY, J. S.; KOSSMANN, E. H. (Eds.). Britain and The Netherlands: 
papers delivered to the Oxford-Netherlands Historical Conference 1959. London: Chatto \& Windus, 1960.

HOCHSTRASSER, Julie Berger. Still life and trade in the Dutch golden age. New Haven: Yale University Press, 2007.

ISRAEL, Jonathan. Dutch primacy in world trade, 1585-1740. Oxford: Oxford University Press, 1989.

ISRAEL, Jonathan. The Dutch republic: its rise, greatness and fall, 1477-1806. Oxford: Oxford University Press, 1995.

JOPPIEN, Ruud. The Dutch Vision of Brazil: Johan Maurits and his artists in BOOGAART, E. van den (Ed.) Johan Maurits van Nassau-Siegen, 1604-1679: a humanist prince in Europe and Brazil, essays on the occasion of the tercentenary of his death. The Hague: The Johan Maurits van Nassau Stichting, 1979.

LAGO, Pedro Corrêa; LAGO, Bia Corrêa do. Frans Post \{1612-1680\}: obra completa. Rio de Janeiro: Capivara, 2006.

LEVESQUE, Catherine. Journey through landscape in seventeenth-century Holland: the Haarlem print series and Dutch identity. University Park: The Pennsylvania State University Press, 1994.

MANDER, Karel van. Het Schilder-Boeck (facsimile van de eerst uitgave 1604). Utrecht: Davaco Publishers, 1969.

MASON, Peter. Infelicities: representations of the exotic. Baltimore: The John Hopkins University Press, 1998.

MELION, Walter S. Shaping the Netherlandish canon. Karel van Mander's Schilder-Boeck. Chicago: The University of Chicago Press, 1991.

MELLO, Evaldo Cabral de. O negócio do Brasil: Portugal, os Países Baixos e o Nordeste, 1641-1669. Rio de Janeiro: Topbooks, 2003.

NIEUHOF, Joan. Memorável viagem marítima e terrestre ao Brasil. Traduzido do inglês por Moacir N. Vasconcelos; confronto com a edição holandesa de 1682, introdução, notas, crítica bibliográfica e bibliografia por José Honório Rodrigues. Belo Horizonte / São Paulo: Ed. Itatiaia / Ed. da Universidade de São Paulo, 1981. Tradução do livro de Johan Nieuhof, Gedenkweerdige Brasiliaense Zee- en Lant- Reize... Amsterdam, door de Weduwe van Jacob van Meurs, op de Keisers-gracht, 1682. 
OLWIG, Kenneth Robert. Landscape, nature and the body politic: from Britain's

Renaissance to America's New World. Madison, The University of Wisconsin Press, 2002.

PRICE, J. L. Holland and the Dutch republic in the seventeenth century: the politics of particularism. Oxford: Clarendom Press, 1994.

SOUSA-LEÃO, Joaquim de. Frans Post 1612-1680. Amsterdam/Rio de Janeiro: A. L. van Gendt \& Co./Kosmos, 1973.

SPICER, Joaneath. A pictorial vocabulary of otherness. Roelandt Saverij, Adam Willarts and the representation of foreign coasts in: FALKENBURG, Reindert (ed.) Natuur en landschap in de Nederlandse kunst 1500-1850. Zwolle: Waanders Uitgevers, 1998.

STECHOW, Walter. Dutch landscape painting of the seventeenth century. Londres, Phaidon: 1966.

VIEIRA, Daniel de Souza Leão. Frans Post, a paisagem e o exótico: o imaginário do Brasil na cultura visual da Holanda do século XVII in: VIEIRA, Hugo Coelho; GALVÃO, Nara Neves Pires; e SILVA, Leonardo Dantas (orgs.). Brasil Holandês: história, memória e patrimônio compartilhado. São Paulo: Alameda, 2012.

VIEIRA, Daniel de Souza Leão. Da história é o olho a geografia: paisagem política e cultura visual nos Países Baixos do século XVII. Saeculum - Revista de História, João Pessoa: UFPB, N. 28, pp. 29-49, jan/jun 2013.

WATJEN, Hermann. O domínio colonial holandês no Brasil: um capítulo da história colonial do século XVII. [1938] Recife: CEPE, 2004. 